\title{
The application of acupuncture in obstetrics and gynecology: a bibliometric analysis based on Web of Science
}

\author{
Long $\mathrm{Wu}^{1}$, Yuan $\mathrm{Li}^{2}$, Pei Yu${ }^{1}$, Huanhuan $\mathrm{Li}^{2}$, Shuai $\mathrm{Ma}^{2}$, Shan Liu ${ }^{2}$, Minghui Liu ${ }^{2}$, Wen Yu${ }^{1}$ \\ ${ }^{1}$ Department of Obstetrics and Gynecology, Beijing Chaoyang Hospital, Capital Medical University, Beijing, China; ${ }^{2}$ Medical Center for Human \\ Reproduction, Beijing Chao-Yang Hospital, Capital Medical University, Beijing, China \\ Contributions: (I) Conception and design: L Wu, Y Li; (II) Administrative support: H Li; (III) Provision of study materials or patients: S Ma, S Liu; (IV) \\ Collection and assembly of data: L Wu, P Yu, H Li, S Ma, S Liu, M Liu, W Yu; (V) Data analysis and interpretation: L Wu, Y Li; (VI) Manuscript \\ writing: All authors; (VII) Final approval of manuscript: All authors. \\ Correspondence to: Yuan Li. Medical Center for Human Reproduction, Beijing Chao-Yang Hospital, Capital Medical University, 8 Gongren Tiyuchang \\ Nanlu, Chaoyang District, Beijing 100020, China. Email: cyliyuan@126.com.
}

Background Acupuncture therapy has a wide range of applications in obstetrics and gynecology, especially for patients with reproductive issues, irregular menstruation, dysmenorrhea, and pelvic inflammatory disease. In recent decades, acupuncture therapy has gradually attracted the attention of professionals in China and overseas due to its beneficial effects, and has been the focus of many studies. This study aimed to conduct a statistical analysis of the relevant literature to understand the current application and research status of acupuncture in obstetric and gynecologic diseases.

Methods: A search of the SCI-EXPANDED database in the Web of Science Core Collection (WOSCC) was performed. Search strategy included two formulas: \#1 WC=Obstetrics \& Gynecology, limited: index =SCI-EXPANDED time span=all years; \#2 subject: (ACUPUNCTURE-MOXIBUSTION) OR subject: (ACUPUNCTURE) OR subject: (MOXIBUSTION), limited: index=SCI-EXPANDED time span=all years. The final result was acquired by searching \#1 AND \#2. CiteSpace software was used to analyze and visualize the annual distribution of articles, and the distributions of disciplines, countries/institutions, journals, and authors. Keywords were used to infer the application of acupuncture in obstetrics and gynecology.

Results: A total of 593 research literatures, including 323 original articles, were retrieved. Since 1972, the number of literatures has shown a general increase. Studies on reproductive medicine accounted for the highest proportion of the retrieved literatures (139, 23.44\%). The United States (25.5\%), China (14.0\%), Germany $(7.6 \%)$, Australia $(7.3 \%)$, and Sweden $(7.1 \%)$ were the main contributors. The centrality index showed that the United States (0.19), the United Kingdom (0.19), and Germany (0.16) had the closest cooperation. The retrieved literatures covered 15 subdivision areas, including menstruation, embryo transfer, production, and pelvic pain. Obstetrics \& Gynecology, Cochrane Database of Systematic Reviews, and American Fournal of Obstetrics and Gynecology were found to be the most influential journals. The most frequently cited keywords were acupuncture (intensity $=5.5326$ ), low back pain (intensity $=5.0506$ ), and pregnancy (intensity $=4.7016)$.

Conclusions: Acupuncture is receiving an increasing amount of attention in obstetrics and gynecology, and international cooperation in research in this field is also increasing.

Keywords: Acupuncture; obstetrics and gynecology; bibliometric analysis

Submitted Dec 09, 2020. Accepted for publication Mar 20, 2021.

doi: $10.21037 / \mathrm{apm}-21-477$

View this article at: http://dx.doi.org/10.21037/apm-21-477 


\section{Introduction}

Acupuncture, an important form of Traditional Chinese Medicine (TCM), has a wide range of applications, including in the treatment of motor system pain, migraine, digestive system function regulation, and obstetrics and gynecology (1-5). For some patients with obstetric and gynecologic diseases, especially those with reproductive issues, irregular menstruation, dysmenorrhea, and pelvic inflammatory disease, the beneficial effects of acupuncture are clear $(6,7)$. In recent decades, acupuncture has gradually attracted the attention of professionals in China and overseas, and a large number of studies have been carried out. However, even with the increase in research and the improvement in the quality of research design, studies have failed to produce consistent conclusions $(8,9)$. Bibliometric analysis uses statistical methods to qualitatively and quantitatively assess the research trends of a literature database and its characteristics. It can not only help scholars grasp the development trends and research direction of a specific research field, but it can also be used to evaluate the relevance of journals, institutions, and countries in specific research fields. It can also provide a basis for the formulation of clinical guidelines. Visual analysis mainly refers to the use of graphical methods to clearly and effectively display and communicate information. At its core is the use of computer image processing technology to visualize and visually represent data and the interaction relationship between different data $(10,11)$. In the past, acupuncture and obstetrics and gynecology have individually been the focus of quantitative analyses $(11,12)$; however, no report on the application of acupuncture in the field of obstetrics and gynecology currently exists. Therefore, in this study, we aimed to conduct a statistical analysis of relevant literature to understand the current application and research status of acupuncture in obstetric and gynecologic diseases.

\section{Methods}

\section{Data source}

The SCI-EXPANDED database in the Web of Science Core Collection (WOSCC) served as the data source for the literature search. The date of retrieval was November 14, 2020 (WOSCC database updated on November 13, 2020).

\section{Search strategy}

Search strategy included two formulas: \#1 WC=Obstetrics
\& Gynecology, limited: index=SCI-EXPANDED time span=all years; \#2 subject: (ACUPUNCTUREMOXIBUSTION) OR subject: (ACUPUNCTURE) OR subject: (MOXIBUSTION), limited: index=SCI -EXPANDED time span=all years. The final result was acquired by searching \#1 AND \#2.

All search results and cited references were exported from the database in plain text format, and the Citespace software was used to analyze the annual publication status, the keywords, and the subject, country/institution, journal, and author distributions. The keywords were used to infer the application of acupuncture in obstetrics and gynecology.

\section{Statistical analysis}

In present descriptive study, all data were expressed as number and percentage. We only show the current status of researches of acupuncture in obstetrics and gynecology.

\section{Results}

\section{Basic results}

A total of 593 relevant research literatures were retrieved, including 323 original papers, 96 reviews, 74 conference reports, 55 letters from readers, and 40 documents classified by editors. The total number of citations was 10,159 , the $\mathrm{H}$-index count was 54 , and the average number of citations per item was 17.13 (Table 1). With the papers classified by subject, reproductive medicine accounted for the largest proportion of the retrieved literatures (Table 2).

\section{Annual distribution of literature}

The scope of the search was from 1900 to November 14, 2020; however, as the first relevant document was published in 1972, the results cover 1972 to November 14, 2020. Since 2000, more than 10 articles have been published each year, with the highest number of articles (45 articles) published in 2011 (Table 3, Figure 1). Since 1998, the number of citations has increased significantly, with 2019 having the highest number of citations (Figure 2).

\section{Distribution of countries and institutions}

CiteSpace V software was used for map visualization of publication countries and institutions (Figure 3): $\mathrm{N}=23, \mathrm{E}=34$ $(\mathrm{N}$ represents the number of network nodes, $\mathrm{E}$ represents 
Table 1 Search results by document type

\begin{tabular}{lcc}
\hline Literature type & Records & \% of 593 \\
\hline Article & 323 & 54.47 \\
Review & 96 & 16.19 \\
Meeting abstract & 74 & 12.48 \\
Letter & 55 & 9.28 \\
Editorial material & 40 & 6.75 \\
Proceedings paper & 8 & 1.35 \\
Early access & 7 & 1.18 \\
Correction & 3 & 0.51 \\
Book review & 1 & 0.17 \\
News item & 1 & 0.17 \\
\hline
\end{tabular}

In total, 608 records are listed in the table, including some duplicated records.

Table 2 Top 10 SCI papers by subject distribution

\begin{tabular}{llcc}
\hline Rank & Major & Records & \% of 593 \\
\hline 1 & Obstetrics \& gynecology & 593 & 100 \\
2 & Reproductive biology & 139 & 23.44 \\
3 & Nursing & 26 & 4.38 \\
4 & Pediatrics & 25 & 4.22 \\
5 & Geriatrics \& gerontology & 21 & 3.54 \\
6 & Oncology & 12 & 2.02 \\
7 & General internal medicine & 9 & 1.52 \\
8 & Public environmental & 9 & 1.52 \\
& occupational health & & \\
9 & Women's studies & 9 & 1.52 \\
10 & Urology \& nephrology & 7 & 1.18 \\
\hline SCl, science citation index & &
\end{tabular}

Table 3 Annual distribution of SCI

\begin{tabular}{lcc}
\hline Year of publication & Records & \% of 593 \\
\hline 2020 & 29 & 4.89 \\
2019 & 37 & 6.24 \\
2018 & 24 & 4.05 \\
2017 & 29 & 4.89 \\
2016 & 25 & 4.22 \\
2015 & 29 & 4.89 \\
\hline
\end{tabular}

Table 3 (continued)
Table 3 (continued)

\begin{tabular}{|c|c|c|}
\hline Year of publication & Records & $\%$ of 593 \\
\hline 2014 & 25 & 4.22 \\
\hline 2013 & 27 & 4.55 \\
\hline 2012 & 26 & 4.38 \\
\hline 2011 & 45 & 7.59 \\
\hline 2010 & 37 & 6.24 \\
\hline 2009 & 44 & 7.42 \\
\hline 2008 & 21 & 3.54 \\
\hline 2007 & 29 & 4.89 \\
\hline 2006 & 29 & 4.89 \\
\hline 2005 & 16 & 2.70 \\
\hline 2004 & 18 & 3.04 \\
\hline 2003 & 17 & 2.87 \\
\hline 2002 & 16 & 2.70 \\
\hline 2001 & 12 & 2.02 \\
\hline 2000 & 10 & 1.69 \\
\hline 1999 & 2 & 0.34 \\
\hline 1998 & 6 & 1.01 \\
\hline 1997 & 2 & 0.34 \\
\hline 1996 & 1 & 0.17 \\
\hline 1995 & 2 & 0.34 \\
\hline 1994 & 1 & 0.17 \\
\hline 1993 & 4 & 0.68 \\
\hline 1992 & 3 & 0.51 \\
\hline 1990 & 1 & 0.17 \\
\hline 1989 & 2 & 0.34 \\
\hline 1988 & 1 & 0.17 \\
\hline 1987 & 2 & 0.34 \\
\hline 1985 & 2 & 0.34 \\
\hline 1984 & 1 & 0.17 \\
\hline 1982 & 1 & 0.17 \\
\hline 1980 & 1 & 0.17 \\
\hline 1979 & 1 & 0.17 \\
\hline 1977 & 3 & 0.51 \\
\hline 1976 & 1 & 0.17 \\
\hline 1975 & 5 & 0.84 \\
\hline 1974 & 5 & 0.84 \\
\hline 1972 & 1 & 0.17 \\
\hline
\end{tabular}

$\mathrm{SCl}$, science citation index. 


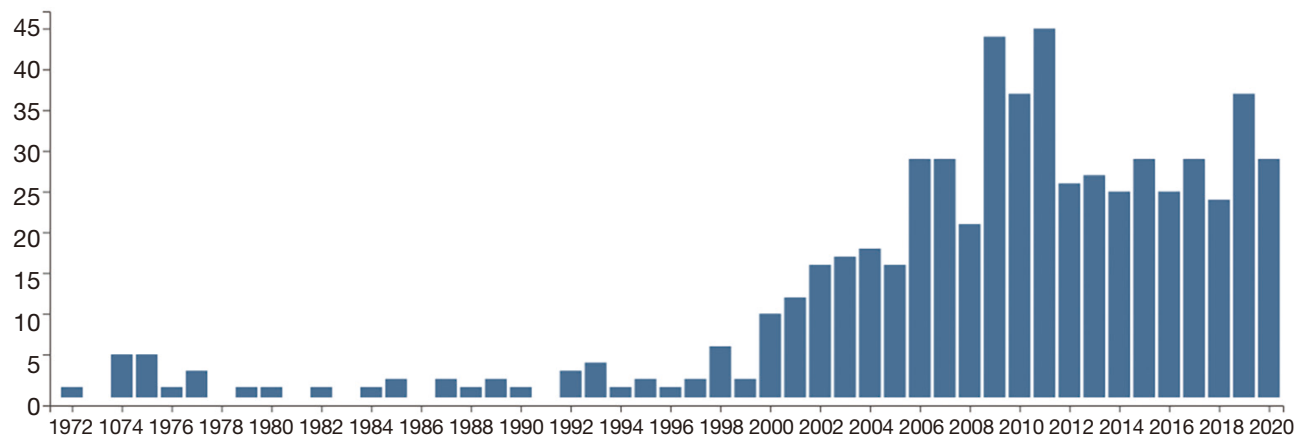

Figure 1 Annual publication trend. The abscissa is the year, and the ordinate is the number of publications.

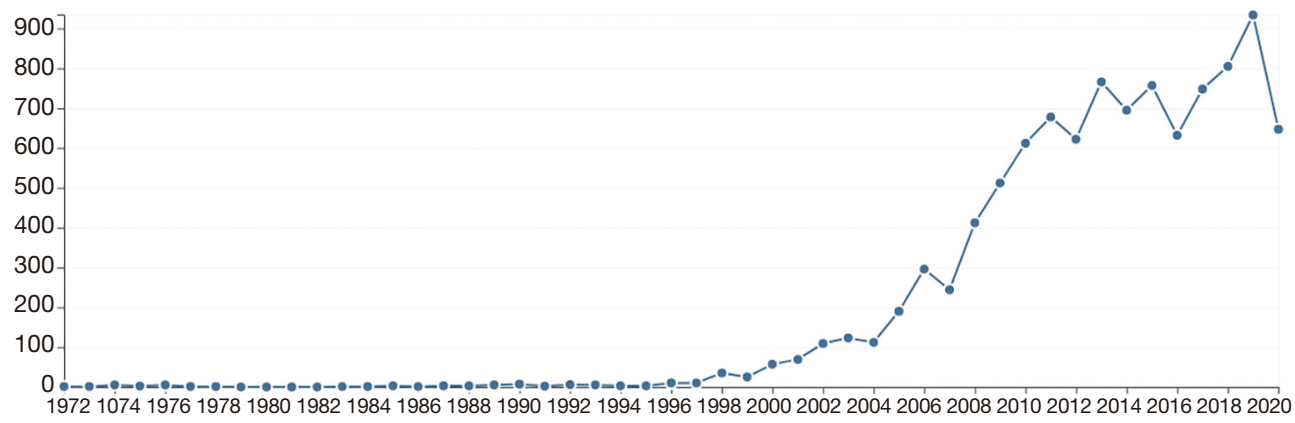

Figure 2 Annual citation trends. The abscissa is the year, and the ordinate is the citation frequency.

the number of connections); institutional visualization maps (Figure 4): $\mathrm{N}=73, \mathrm{E}=42$. During the search period, the top 5 countries in terms of publication volume were the United States, China, Germany, Australia, and Sweden (Figure 3 and Table 4). The top 5 countries ranked by centrality were the United States, the United Kingdom, Sweden, Germany, and Australia. Although China was ranked second for volume, the centrality was low, probably due to a lack of international cooperation. Based on the volume and centrality of publications, it can be inferred that the United States, China, and Germany were the main research forces in the field during the search period, while the United States, the United Kingdom, and Germany had the closest cooperation. The top 5 institutions in terms of publication volume were the University of Exeter (UK), Kyung Hee University (South Korea), University of Plymouth (UK), University of Gothenburg (Sweden), and Harvard University (USA) (Figure 4 and Table 5).

\section{Autbor distribution and co-citation}

In the period from 1972 to November 14, 2020, C. A. Smith was the author with the highest number of papers published (Table 6). Visualization maps of co-authorship and co-citations can provide useful information about influential research teams and potential collaborators, and can help researchers to establish cooperative relationships. The visualization maps showing co-authorship (Figure 5) and cocitation (Table 7 and Figure 6) connections among authors were generated using the CiteSpace V software. During the search period, C. A. Smith ranked highest for both the number of citations and centrality. For the cluster analysis of author co-citations, the cited authors were identified, and then clustering analysis was performed. Then, the index terms of the cited documents were used to mark the category name. A total of 15 clusters were found in the cited literature (Figure 7), and the research categories, identified from the index terms, are listed in Table 8.

\section{Distribution of journals}

The 593 retrieved articles were published in 76 journals, among which, 10 journals each published more than 20 articles (Table 7). These 10 journals published $55.31 \%$ of the total articles (Table 9). Table 10 lists the top 5 journals by centrality and frequency of citations. Based on the results 


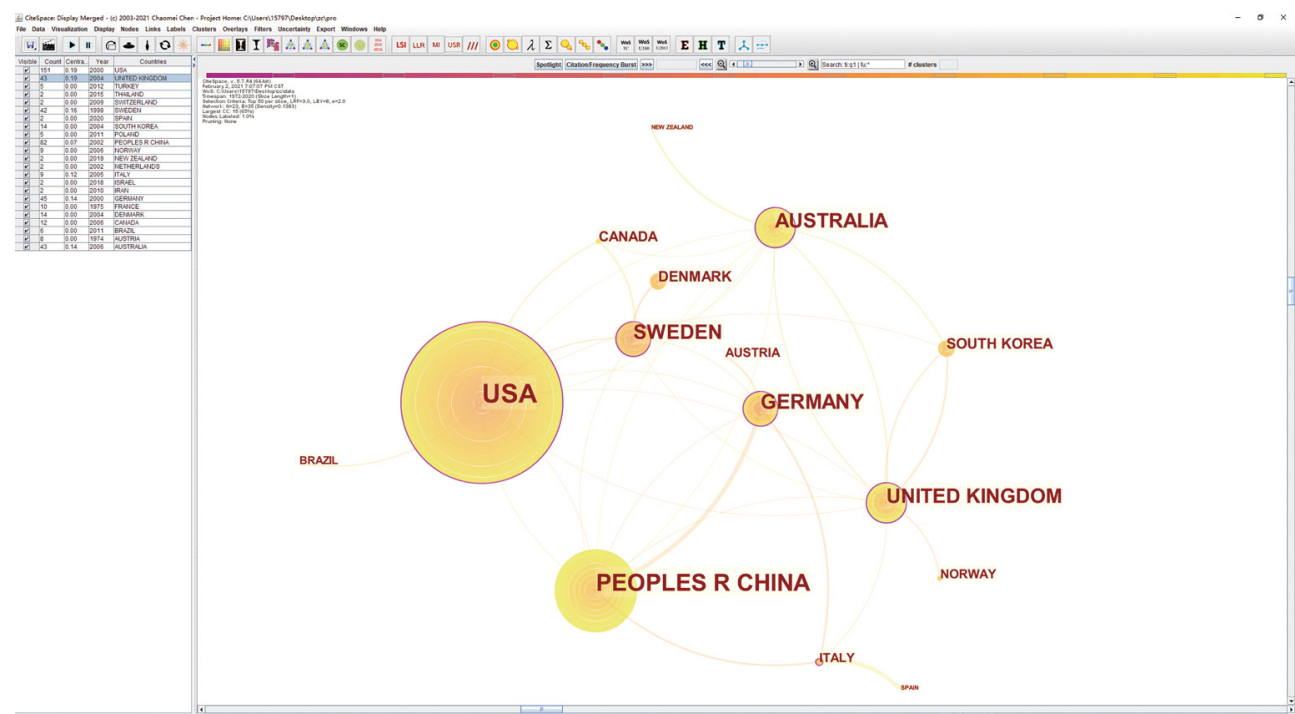

Figure 3 Visualization map of publication countries.

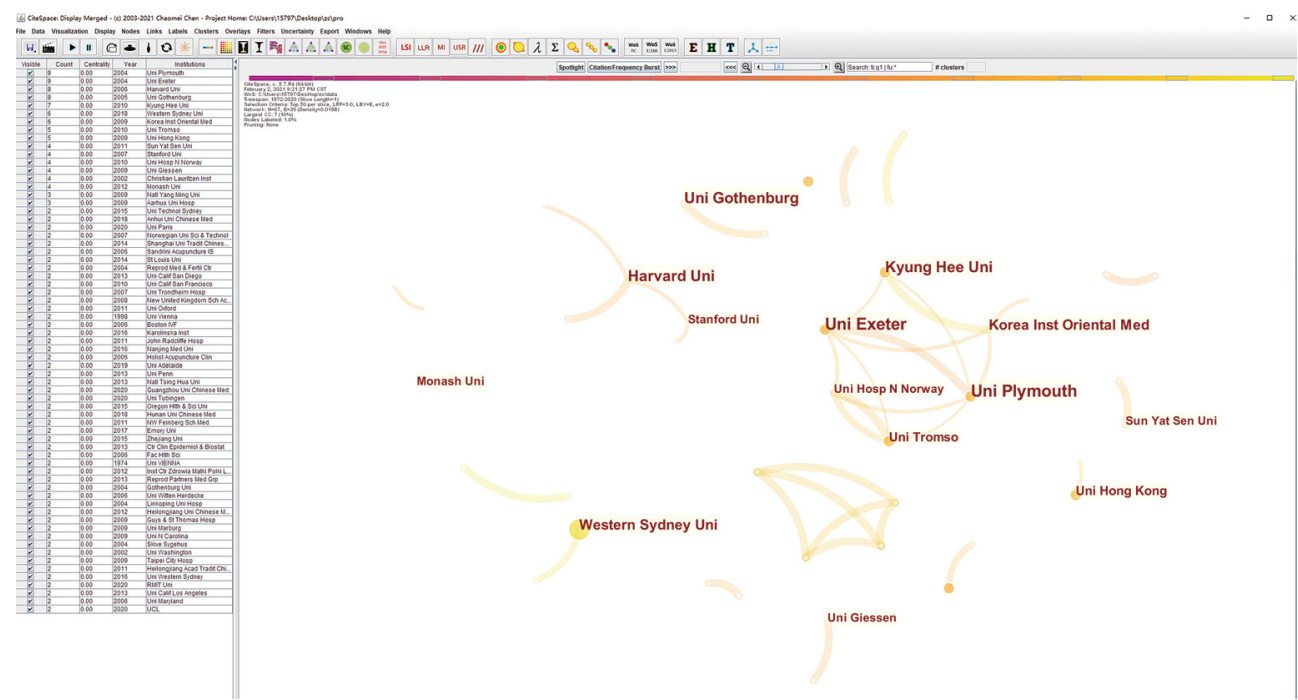

Figure 4 Visualization map of publication institutions.

Table 4 Top 5 countries in terms of publication volume and centrality

\begin{tabular}{lcccc}
\hline \multirow{2}{*}{ Rank } & \multicolumn{2}{c}{ Publication volume } & \multicolumn{2}{c}{ Centrality } \\
\cline { 2 - 4 } \cline { 3 - 5 } & Countries & Papers, $n(\%)$ & Countries & Centrality \\
2 & USA & $151(25.46)$ & USA & 0.19 \\
3 & China & $83(14.00)$ & United Kingdom & 0.19 \\
4 & Germany & $45(7.59)$ & Sweden & 0.16 \\
5 & Australia & $43(7.25)$ & Germany & 0.14 \\
\hline
\end{tabular}


Table 5 Top 5 institutions for publication volume and Top 3 institutions for centrality

\begin{tabular}{llllll}
\hline \multirow{2}{*}{ Rank } & \multicolumn{2}{c}{ Publication volume } & & \multicolumn{2}{c}{ Centrality } \\
\cline { 2 - 3 } & Institution & Papers & & Institution & Centrality \\
\hline 1 & $\begin{array}{l}\text { University of } \\
\text { Exeter }\end{array}$ & 9 & $\begin{array}{l}\text { Kyung Hee } \\
\text { University }\end{array}$ & 0.01 \\
2 & $\begin{array}{l}\text { Kyung Hee } \\
\text { University }\end{array}$ & 9 & & Harvard University & 0.01 \\
3 & $\begin{array}{l}\text { University of } \\
\text { Plymouth }\end{array}$ & 9 & Korea Institute of & 0.01 \\
4 & $\begin{array}{l}\text { University of } \\
\text { Gothenburg }\end{array}$ & 8 & & \\
& $\begin{array}{l}\text { Oriental Medicine } \\
\text { Harvard } \\
\text { University }\end{array}$ & 8 & & \\
\end{tabular}

Table 6 Top 10 authors (43 papers in total)

\begin{tabular}{lll}
\hline Rank & Authors & Papers \\
\hline 1 & C. A. Smith & 7 \\
2 & P. Wozniak & 4 \\
3 & E. Stenervictorin & 4 \\
4 & I. Gerhard & 4 \\
5 & K. Sterzik & 4 \\
6 & M. S. Lee & 4 \\
7 & E. Strehler & 4 \\
8 & P. Oszukowski & 4 \\
9 & M. Hammar & 4 \\
10 & T. Stetkiewicz & 4 \\
\hline
\end{tabular}

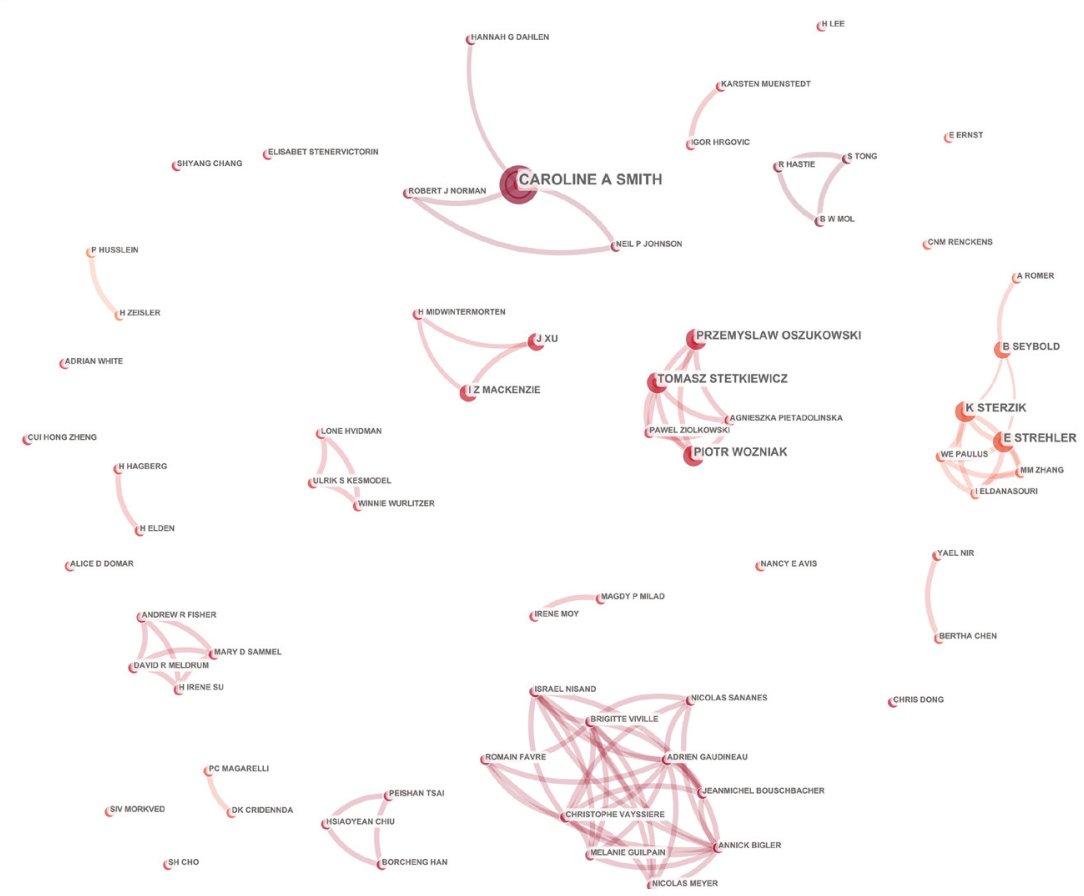

Figure 5 Visualization map showing co-authorship.

Table 7 Top 5 cited authors

\begin{tabular}{lll}
\hline Rank & Authors & Papers \\
\hline 1 & Smith C.A. & 60 \\
2 & Stener-Victorin E. & 55 \\
3 & Paulus W.E. & 51 \\
4 & Smith C. & 45 \\
5 & Dieterle S. & 39 \\
\hline
\end{tabular}

of this analysis, Obstetrics \& Gynecology, Cochrane Database of Systematic Reviews, and American fournal of Obstetrics and Gynecology were the most influential journals.

\section{Research hotspots and frontier trends in the field of acupuncture in obstetrics and gynecology}

A keyword co-occurrence map was generated using CiteSpace V software (Figure 8: $\mathrm{N}=176, \mathrm{E}=1,111$ ). The top 


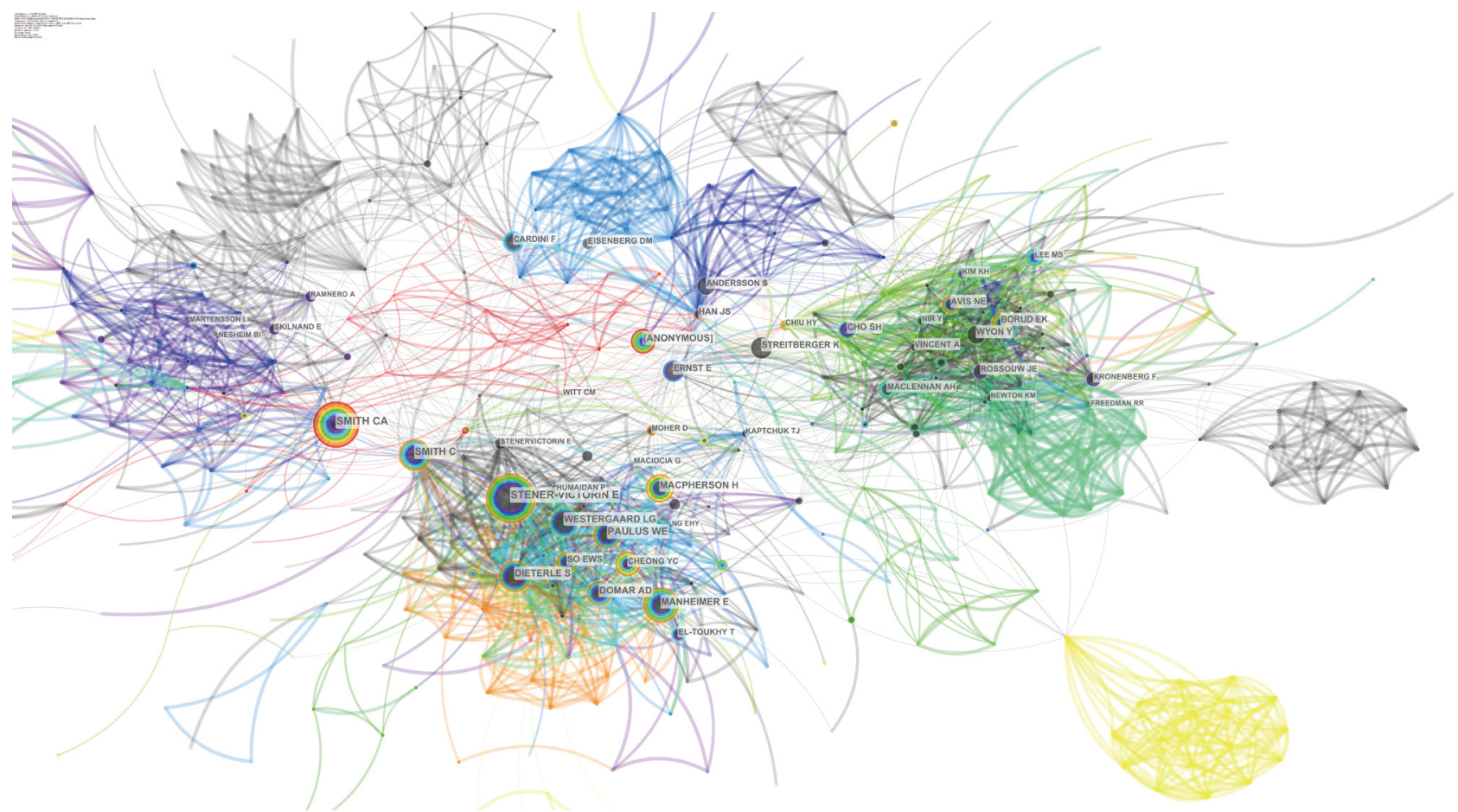

Figure 6 Visualization map of author co-citations.

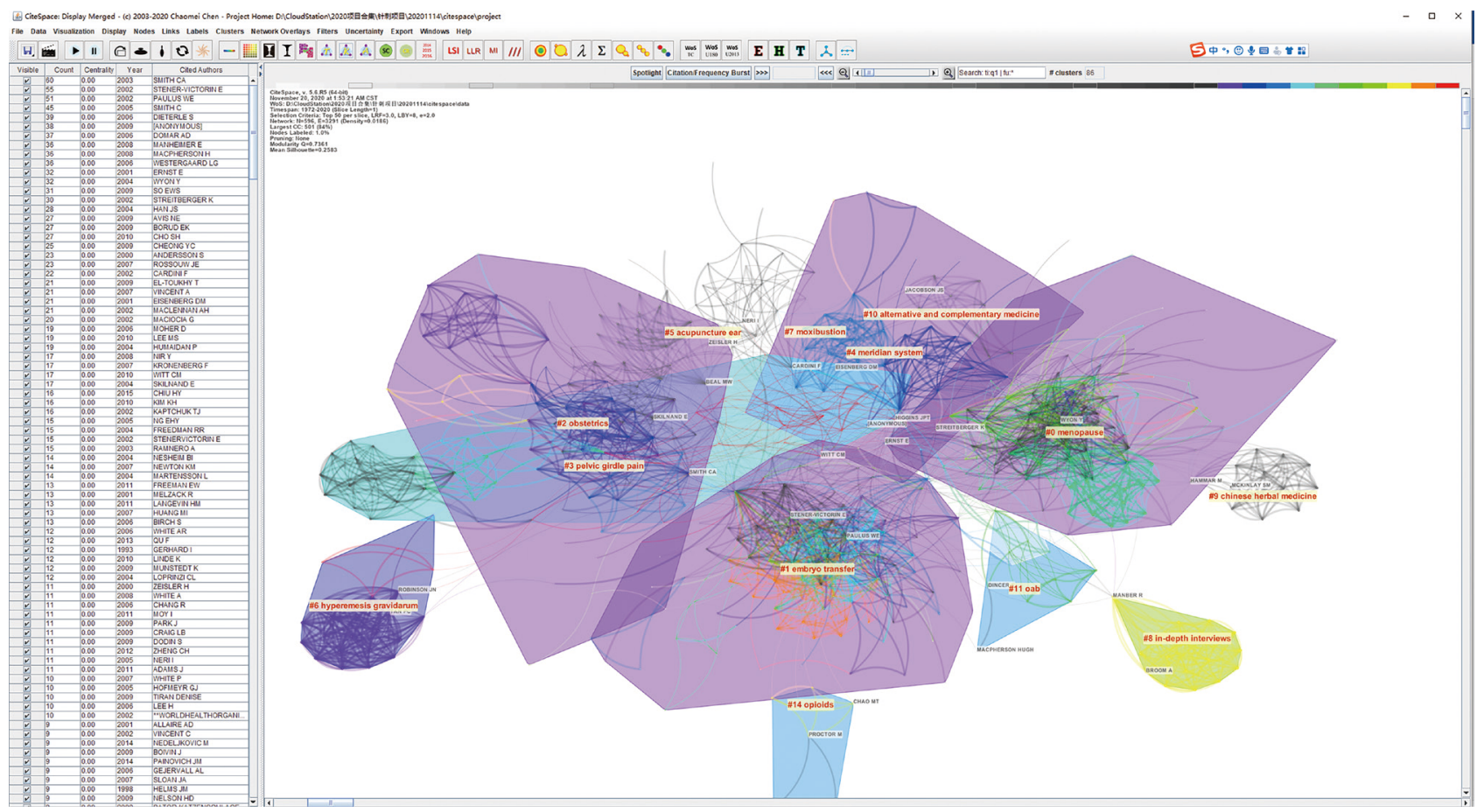

Figure 7 Cited cluster analysis showing the 15 main research areas. 
Table 8 The 15 main research areas among the retrieved papers

\begin{tabular}{ll}
\hline Rank & Classification \\
\hline 1 & Menopause \\
2 & Embryo transfer \\
3 & Obstetrics \\
5 & Pelvic girdle pain \\
6 & Meridian system \\
7 & Acupuncture ear \\
8 & Hyperemesis gravidarum \\
9 & Moxibustion \\
10 & In-depth interviews \\
11 & Chinese herbal medicine \\
14 & Alternative and complementary medicine \\
15 & Over active bladder \\
\hline
\end{tabular}

Table 9 Top 10 journals by volume

\begin{tabular}{|c|c|c|c|}
\hline Journals & Records & $\%$ of 593 & IF [2019] \\
\hline Fertility and Sterility & 72 & 12.14 & 6.31 \\
\hline $\begin{array}{l}\text { Menopause: The Journal of The } \\
\text { North American Menopause } \\
\text { Society }\end{array}$ & 39 & 6.58 & 3.31 \\
\hline $\begin{array}{l}\text { BJOG: An International Journal } \\
\text { of Obstetrics and Gynaecology }\end{array}$ & 35 & 5.90 & 4.66 \\
\hline Human Reproduction & 34 & 5.73 & 5.73 \\
\hline $\begin{array}{l}\text { Geburtshilfe und } \\
\text { Frauenheilkunde }\end{array}$ & 32 & 5.40 & 2.38 \\
\hline $\begin{array}{l}\text { Acta Obstetricia et Gynecologica } \\
\text { Scandinavica }\end{array}$ & 27 & 4.55 & 2.77 \\
\hline Obstetrics \& Gynecology & 24 & 4.05 & 5.52 \\
\hline Climacteric & 23 & 3.88 & 2.57 \\
\hline $\begin{array}{l}\text { Archives of Gynecology and } \\
\text { Obstetrics }\end{array}$ & 21 & 3.54 & 2.28 \\
\hline Maturitas & 21 & 3.54 & 3.63 \\
\hline
\end{tabular}

IF, impact factor.

Table 10 Top 5 journals by citations

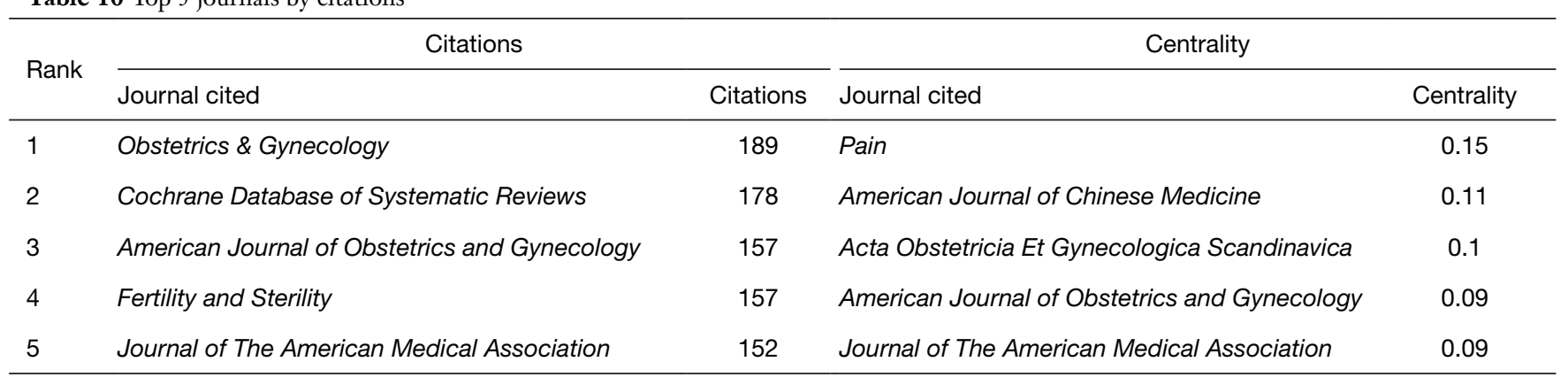

10 keywords in terms of frequency and centrality are listed in Table 11. High-frequency keywords were identified using burst detection in CiteSpace, and the results are shown in Figure 9. Due to the small number of papers included in this analysis, only 3 keywords were identified: acupuncture, low back pain, and pregnancy.

\section{Discussion}

Acupuncture is a treatment method in TCM. It has a good curative effect and an accepted treatment for a wide range of conditions, including obstetric and gynecologic diseases, motor system pain, and gastrointestinal dysfunction. With the deepening integration of Chinese and Western medicine, an increasing number of international researchers have begun to use and pay attention to the therapeutic effect of acupuncture. Researchers have conducted indepth studies on the effects and mechanisms of acupuncture in many fields, and the results are frequently published in professional authoritative journals. Statistical analysis of the published literature can reveal research hotspots and research directions in related fields and give an indication of research prospects. In the present study, our statistical analysis of relevant published research found that the first English-language paper on the application of acupuncture in the treatment of obstetric and gynecologic diseases only appeared in 1972. Research in this field developed slowly until around 2000, when it began to grow rapidly. Furthermore, we found that several countries, research institutions, and researchers are prominent contributors 


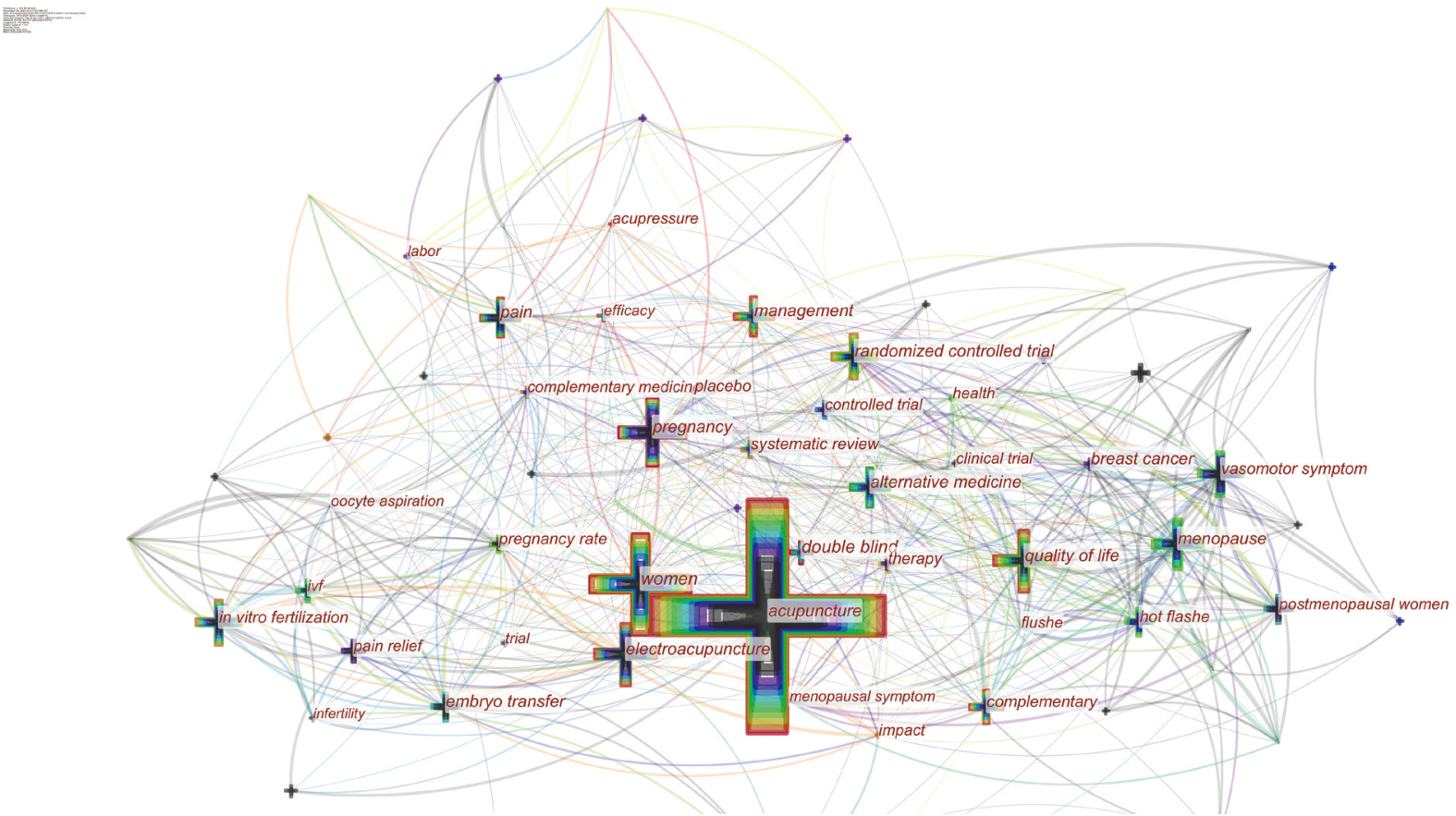

Figure 8 Keyword co-occurrence map.

Table 11 Top 10 keywords

\begin{tabular}{llccrcr}
\hline \multirow{2}{*}{ Rank } & \multicolumn{2}{c}{ Citations } & & & Centrality \\
\cline { 2 - 3 } & Theme & Citations & Theme & Centrality \\
\hline 1 & Acupuncture & 285 & Women & 0.15 \\
3 & Women & Pregnancy & 92 & Acupuncture & 0.14 \\
4 & Electroacupuncture & 57 & Complementary & 0.13 \\
5 & Randomized controlled trial & 54 & Pregnancy & 0.12 \\
6 & Quality of life & 52 & Double blind & 0.12 \\
7 & Menopause & 52 & Pain relief & 0.11 \\
8 & Vasomotor symptom & 40 & Pain & 0.1 \\
9 & Pain & 39 & Alternative medicine & 0.1 \\
10 & In vitro fertilization & 39 & Management & 0.09 \\
\hline
\end{tabular}

\begin{tabular}{lcccccc} 
& \multicolumn{5}{c}{ Top 3 Keywords with the Strongest Citation Bursts } \\
$\begin{array}{lllllll}\text { Keywords } & \text { Year } & \text { Strength } & \text { Begin End } & 1972-2020 \\
\text { Acupuncture } & 1972 & 5.5326 & 1992 & 2001 \\
\text { Low back pain } & 1972 & 5.05 .6 & 2005 & 2010 & - \\
\text { Pregnancy } & 1972 & 4.7016 & 2009 & 2012 & -\end{array}-$ \\
\hline
\end{tabular}

Figure 9 Top 3 keywords with the strongest citation bursts. 
to the field, with research institutions and researchers in the United States, the United Kingdom, and Germany having the closest cooperation. Unfortunately, despite the prominence of traditional medicine in China, Chinese institutions and researchers have published relatively few papers on acupuncture in English journals, and there is relatively little cooperation between domestic research institutions and researchers.

In terms of the research direction, our statistical results show that current research is mainly focused on 15 topics, among which reproduction, menstrual disorders, and pain are research hotspots. In recent years, acupuncture has drawn particular research attention as as a treatment for reproductive issues, with a number of randomized controlled trials having been published, with differing results. A 2017 meta-analysis found that acupuncture may improve women's fertility; however, the authors noted that the evidence of the included studies was relatively weak (13). Meanwhile, a randomized controlled study published in $7 A M A$ the following year showed that compared with sham-acupuncture, real acupuncture failed to significantly increase the live birth rate of in vitro fertilization (IVF) (8). Nevertheless, acupuncture can alleviate anxiety during embryo transfer (14), and it has also been shown to have certain effects on perinatal depression $(15,16)$. Women's pain is another research focus. Some studies have found that acupuncture can reduce lower back pain or pelvic girdle pain in pregnant women as well as pain during childbirth, obtaining high satisfaction $(3,17,18)$. It can also effectively reduce menstrual and fibromyalgia pain in women $(19,20)$.

Based on our in-depth analysis of the literature, we found that the number of papers on acupuncture published in top comprehensive medical journals, including the 4 major comprehensive journals (New England Fournal of Medicine, The Lancet, $7 A M A$, and $B M 7$ ), has increased in recent years. A large number of clinical studies on acupuncture have been published, and in particular, the number of randomized controlled trials is increasing. According to the results of these RCT studies, more evidence will need to be accumulated for the reasonable application of acupuncture in clinical practice. A positive trend in recent years is that Chinese scholars have carried out an increasing number of RCTs, and more and more research results are being published in authoritative journals $(4,5,13,15,21)$. These RCTs designs and results are rigorous and objective, providing solid information for clinicians and researchers.

The current study has some limitations that should be noted. First, to make it easier for scholars from different countries to access and understand the related research, we mainly analyzed English-language documents, and thus, we may have omitted relevant articles published in Chinese. In the future, we intend to explore the application value of acupuncture in obstetrics and gynecology by exploring literature using a more comprehensive search and time span.

\section{Acknowledgments}

Funding: 1351 Talent Training Program (CYMY-201721); 1351 Talent Training Program (CYXX-2017-20); Capital Health Development Scientific Research Project (Independent Innovation, 2020-1-2039); Beijing Health Promotion Foundation (2019-09-05); 2018 Fertility Research Program of Young and Middle-aged PhysiciansChina Health Promotion Foundation

\section{Footnote}

Conflicts of Interest: All authors have completed the ICMJE uniform disclosure form (available at http://dx.doi. org/10.21037/apm-21-477). The authors have no conflicts of interest to declare.

Ethical Statement: The authors are accountable for all aspects of the work in ensuring that questions related to the accuracy or integrity of any part of the work are appropriately investigated and resolved.

Open Access Statement: This is an Open Access article distributed in accordance with the Creative Commons Attribution-NonCommercial-NoDerivs 4.0 International License (CC BY-NC-ND 4.0), which permits the noncommercial replication and distribution of the article with the strict proviso that no changes or edits are made and the original work is properly cited (including links to both the formal publication through the relevant DOI and the license). See: https://creativecommons.org/licenses/by-nc-nd/4.0/.

\section{References}

1. Witt C, Brinkhaus B, Jena S, et al. Acupuncture in patients with osteoarthritis of the knee: a randomised trial. Lancet 2005;366:136-43.

2. Takahashi T. Acupuncture for functional gastrointestinal disorders. J Gastroenterol 2006;41:408-17.

3. Elden H, Ladfors L, Olsen MF, et al. Effects of 
acupuncture and stabilising exercises as adjunct to standard treatment in pregnant women with pelvic girdle pain: randomised single blind controlled trial. BMJ 2005;330:761.

4. Zhao L, Chen J, Li Y, et al. The Long-term Effect of Acupuncture for Migraine Prophylaxis: A Randomized Clinical Trial. JAMA Intern Med 2017;177:508-15.

5. Zhao L, Li D, Zheng H, et al. Acupuncture as Adjunctive Therapy for Chronic Stable Angina: A Randomized Clinical Trial. JAMA Intern Med 2019;179:1388-97.

6. Zhu J, Arsovska B, Kozovska K. Acupuncture Treatment for Fertility. Open Access Maced J Med Sci 2018;6:1685-7.

7. Shetty GB, Shetty B, Mooventhan A. Efficacy of Acupuncture in the Management of Primary Dysmenorrhea: A Randomized Controlled Trial. J Acupunct Meridian Stud 2018;11:153-8.

8. Smith CA, de Lacey S, Chapman M, et al. Effect of Acupuncture vs Sham Acupuncture on Live Births Among Women Undergoing In Vitro Fertilization: A Randomized Clinical Trial. JAMA 2018;319:1990-8.

9. Wu XK, Stener-Victorin E, Kuang HY, et al; PCOSAct Study Group. Effect of Acupuncture and Clomiphene in Chinese Women With Polycystic Ovary Syndrome: A Randomized Clinical Trial. JAMA 2017;317:2502-14.

10. Yadava SM, Patrick HS, Ananth CV, et al. Top-cited articles in the Journal: a bibliometric analysis. Am J Obstet Gynecol 2019;220:12-25.

11. Brandt JS, Hadaya O, Schuster M, et al. A Bibliometric Analysis of Top-Cited Journal Articles in Obstetrics and Gynecology. JAMA Netw Open 2019;2:e1918007.

12. Liang YD, Li Y, Zhao J, et al. Study of acupuncture for low back pain in recent 20 years: a bibliometric analysis via CiteSpace. J Pain Res 2017;10:951-64.

13. Yun L, Liqun W, Shuqi Y, et al. Acupuncture for infertile women without undergoing assisted reproductive techniques (ART): A systematic review and meta-analysis.
Medicine (Baltimore) 2019;98:e16463.

14. Smith CA, de Lacey S, Chapman M, et al. The effects of acupuncture on the secondary outcomes of anxiety and quality of life for women undergoing IVF: A randomized controlled trial. Acta Obstet Gynecol Scand 2019;98:460-9.

15. Ormsby SM, Dahlen HG, Smith CA. Women's experiences of having depression during pregnancy and receiving acupuncture treatment-A qualitative study. Women Birth 2018;31:469-78.

16. Li W, Yin P, Lao L, et al. Effectiveness of Acupuncture Used for the Management of Postpartum Depression: A Systematic Review and Meta-Analysis. Biomed Res Int 2019;2019:6597503.

17. Martins ES, Tavares TMCL, Lessa PRA, et al. Acupuncture treatment: multidimensional assessment of low back pain in pregnant women. Rev Esc Enferm USP 2018;52:e03323.

18. Woo HL, Ji HR, Pak YK, et al. The efficacy and safety of acupuncture in women with primary dysmenorrhea: A systematic review and meta-analysis. Medicine (Baltimore) 2018;97:e11007.

19. Trutnovsky G, Schneeweiss M, Pregartner G, et al. Prenatal acupuncture: Women's expectations and satisfaction and influence on labor. Birth 2018;45:210-6.

20. Mist SD, Jones KD. Randomized Controlled Trial of Acupuncture for Women with Fibromyalgia: Group Acupuncture with Traditional Chinese Medicine Diagnosis-Based Point Selection. Pain Med 2018;19:1862-71.

21. Guo T, Jia M, Jin Y, et al. Acupuncture for perimenopausal insomnia: A systematic review and meta-analysis protocol. Medicine (Baltimore) 2018;97:e11083.

(English Language Editor: J. Reynolds)
Cite this article as: Wu L, Li Y, Yu P, Li H, Ma S, Liu S, Liu $\mathrm{M}, \mathrm{Yu} \mathrm{W}$. The application of acupuncture in obstetrics and gynecology: a bibliometric analysis based on Web of Science. Ann Palliat Med 2021;10(3):3194-3204. doi: 10.21037/apm-21477 